\title{
A Simple Analytical Model for Estimating Long-term Productivity of Multi-fractured Shale Gas Wells
}

\author{
Zheng Zhang, Bin Wang \\ University of Louisiana at Lafayette
}

\begin{abstract}
Shale gas production has been successful developed over the past several years. The horizontal well with multistage hydraulic fracturing has proven to be an effective operation of development these unconventional reservoirs. Most of modeling effort has been made for earlier liner flow. A simple analytical model for long-term shale gas production evaluation is still lacking. This work fill this gap. A simple and accurate mathematical model are developed which considering linear flow in both shale matrix and fracture. It can describe the longterm shale gas production with pseudo steady state flow. The model is verified against a Fayetteville field case data. The difference between the production rate given by the model and measured data was found to be less than $10 \%$. The effect of fracture geometry parameter on long-term production rate are also investigated. The results show the fracture spacing and fracture length is the most dominant factors on thelong-term shale gas production performance.This model provides reservoir engineers a simple and accurate tool for predicting, evaluating and optimizing the long-term performance of shale gas wells.
\end{abstract}

\section{INTRODUCTION}

The combination of horizontal drilling and multistagehydraulic fracturing technology has made possible the current gas production from shale gas reservoirsin the United States, as well as the global fast growinginvestment in shale gas exploration and development. Shale-gas reservoirs are organic-rich formations, varying fromone shale formation to another, even within the formation itself,and they serve as both reservoir and source rock. Gas in the shaleis mainly composed of free gas in natural fractures and matrixpore structure and adsorbed gas on the surface of shale matrix andin organic materials. The uncertainties of reservoir and fractureparameters have significant effect on shalegas production.

There have been a significant number of attempts in recent years to evaluate numerically the well performance for earlier-time transient flow in unconventional gas reservoirs (Britt and Smith 2009; Fan et al. 2010; Cipolla et al. 2010; Du et al. 2009; Li et al. 2011; Dahaghi and Mohaghegh. 2011; Novlesky et al. 2011; Yu et al. 2014; Mattar et al. 2008; Freeman et al. 2009). However, to the best of our knowledge, few of analytical or semi-analytical models consider long-term pseudo steady state flow shale gas production (Fig. 1). Raghavan (1993) developed an analytical model to evaluate the well production ofhorizontal wells with multiple fractures. But the flow in the fractures was not considered. Guo and Schechter (1997) presented an analytical model coupling reservoir linear flow and fracture linear flow. But that model only considersa single fracture cases. Yuan and Zhou (2010) proposed a simple model to predict inflow performance in fractured horizontal wells which is applicable for both fractured wells and non-fractured wells. But it only valid for steady state flow condition. Vargas et al (2015) extended Guo's model to predict transient pressure behavior with variable flow-rate.

This paper presents a simple model for predicting gas production of multi-fractured horizontal wells at pseudo steady state condition. It provides reservoir engineers a simple and accurate tool for predicting, evaluating and optimizing the long-term performance of shale gas wells. A good agreement was observed between the actual production rate and predicted one for Fayetteville shale well. The effect of fracture geometry parameter on gas production has been analyzed. 

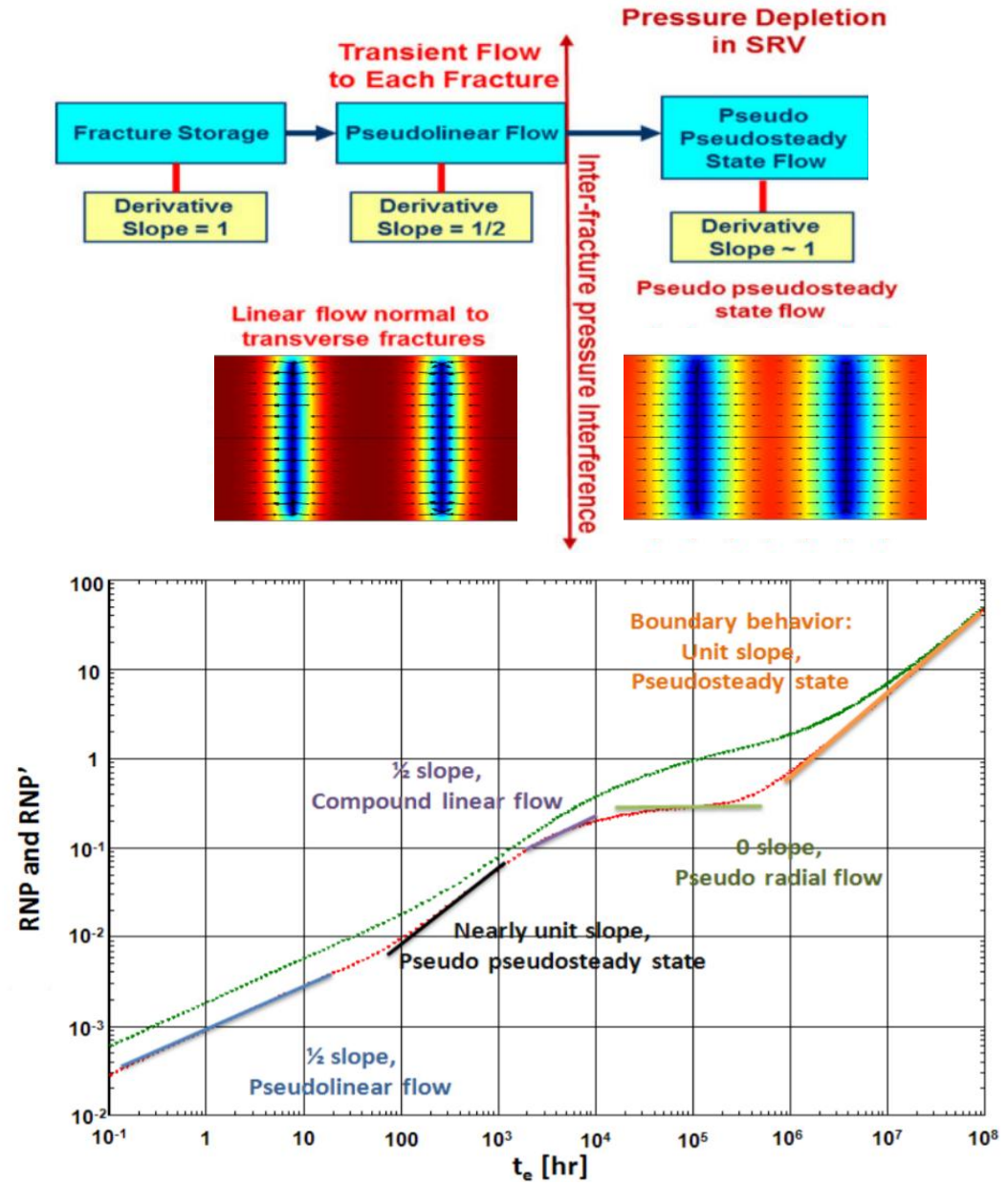

Fig. 1 Potential flow regimes during shale gas production (Song. 2011)

\section{Model Development}

The analytical model considering liner flow in the fracture and matrix.Several assumptions are stated as follows:

1) The wellbore-flow modeling and fracture skin is not included in this paper

2) The shale reservoir is homogeneous and isotropic with uniform thickness and constant porosity.

$$
\begin{gathered}
Q_{g}=\frac{5.87 \times 10^{-5} n_{f} k_{m} h\left(\bar{p}^{2}-p_{w}^{2}\right)}{\mu T S_{f} \sqrt{c}\left[\frac{1}{1-e^{-\sqrt{c x_{f}}}}-\frac{1}{3 x_{f} \sqrt{c}}\right]} \\
c=\frac{96 k_{m}}{k_{f} w S_{f}}
\end{gathered}
$$

3) Fracture are identical and fully penetrate the reservoir thickness.

4) Gravity effect is negligible.

5) Single phase gas flow is considered.

The analytical solution of well inflow equation for pseudo steady state flow can be expressed as follows:
Where $Q_{g}$ is the gas production rate, Mscf/d; $n_{f}$ is the number of fracture, dimensionless; $k_{m}$ is the matrix permeability, md; $h$ is the pay zone thickness, $\mathrm{ft}$; $\bar{p}$ is the average formation pressure in psia. $p_{w}$ is wellbore pressure, psia; $\square$ is gas viscosity. $T$ is the formation temperature, $\mathrm{R} ; S_{f}$ is fracture spacing, $\mathrm{ft} ; x_{f}$ is the fracture half length.

\section{Methodology Verification}

A field cases (Song. 2011) were performed to verify the accuracy and applicability of the proposed analytical model. The basic model parameters for all cases are summarized in Table 1.Song (2011) presented a rate-normalized pressure (RNP) method to quantify the flow region, shale permeability, average half-length and effective stimulated reservoir volume (SRV) based on 
production data. In the case of Fayetteville shale, the well was stimulated by 72 stages fracturing with a single, perforated interval for each stage. The well production rate declines form $2500 \mathrm{Mscf} / \mathrm{d}$ to 50 $\mathrm{Mscf} / \mathrm{d}$ over a 1.8 years production period.
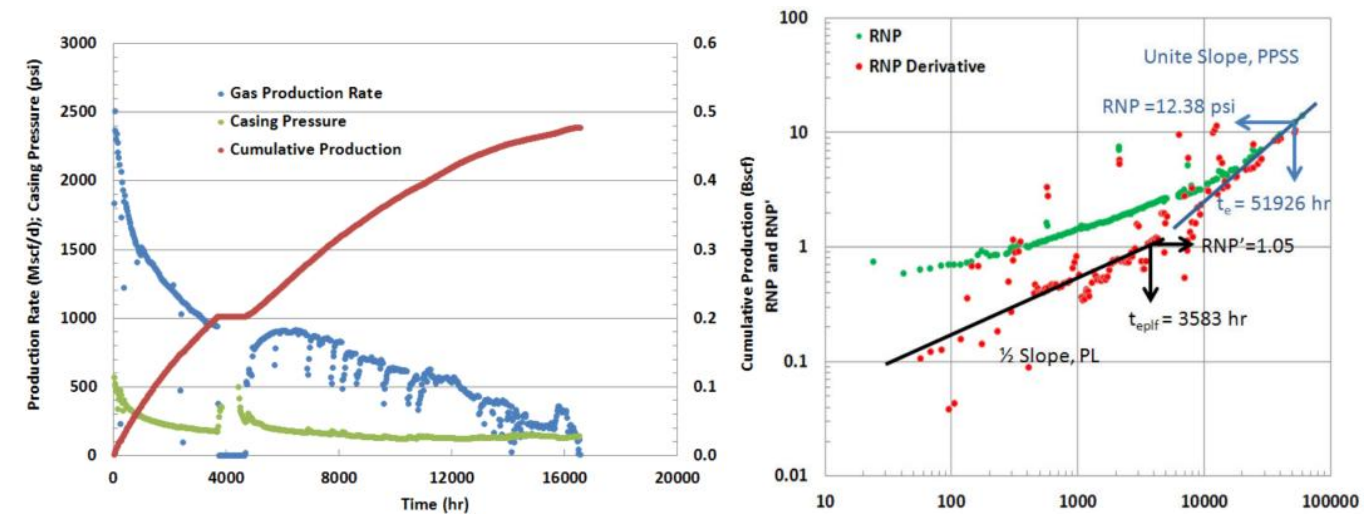

Fig. 2-Fayetteville shale well production and RNP data (Song. 2011)

Based on the well RNP figure (Fig. 2above), a unit slop indicates a pseudo steady state flow period occurs at about 1.7-1.8 years. By using RNP analysis, the fracture half-length is64ft, Matrix permeability is 2.2e-4 md, effective SRV is 7.6e6 $\mathrm{ft}^{3}$. The final bottom hole pressure is measured about 150 psi. The gas viscosity can be calculated based on average

$$
\frac{G_{p}}{G_{i}}=1-\frac{\bar{p} / z}{p_{i} / z_{i}}
$$

Thus,

$$
\bar{p} / z=\left(1-G_{p} / G_{i}\right) /\left(p_{i} / z_{i}\right)=(1-0.48 / 1.78)(1050 / 0.86)=890
$$

Based on Hall-Yarborough correction (Guo. 2017), the theoretical fracture permeability can be estimated average pressure can be calculated in 765 psi.The using cubic law (Kim and Moridis, 2015):

$$
k_{f}=\alpha_{c} \frac{h^{2}}{12}
$$

Where, $\mathrm{C}$ is the correction factor considering fracture roughness, 0.14 used in this paper. Assuming the fracture width is 0.05 inch. All of parameters are summarized in Table. 1. Substituting these data into

Mscf/day. As shown in Fig. 2, thediscrepancy between predicted value (66.01) and measured value $(60-70)$ is within $10 \%$. Eqs. 1-2 yields the gas production rate of 46.15

Table 1-Reservoir and fluid flow properties (Song. 2011)

\begin{tabular}{crr} 
Property & Unit & Value \\
\hline Horizontal well length, $\mathrm{L}$ & $\mathrm{ft}$ & 3528 \\
Initial reservoir pressure, $\mathrm{P}_{\mathrm{i}}$ & $\mathrm{psia}$ & 1050 \\
Average formation pressure, $\mathrm{p}$ _bar & $\mathrm{psia}$ & 765 \\
Reservoir thickness, $\mathrm{h}$ & $\mathrm{ft}$ & 322 \\
Reservoir temperature, $\mathrm{T}$ & $\mathrm{R}$ & 580 \\
Gas viscosity, $\square$ & $\mathrm{cp}$ & 0.01159 \\
Bottom hole pressure, $\mathrm{p}_{\mathrm{w}}$ & $\mathrm{psia}$ & 150 \\
Matrix permeability, $\mathrm{k}_{\mathrm{m}}$ & $\mathrm{md}$ & $2.2 \mathrm{e}-4$ \\
\hline Total number of fractures, $\mathrm{n}_{\mathrm{f}}$ & - & 72 \\
Effective fracture spacing, $\mathrm{s}_{\mathrm{f}}$ & $\mathrm{ft}$ & 49 \\
Fracture half-length, $\mathrm{x}_{\mathrm{f}}$ & $\mathrm{ft}$ & 90 \\
Fracture width, $\mathrm{w}$ & $\mathrm{in}$ & 0.05 \\
Fracture permeability, $\mathrm{k}_{\mathrm{f}}$ & $\mathrm{md}$ & 18817
\end{tabular}




\section{Sensitivity Study}

For hydraulic fracture operation, the fracture permeability is dependent on fracture width (Eq. 5) and the number of fractures is dependent on fracture spacing. Thus, three key operational parameters were selected as design variables in this study: fracture spacing, $S_{f}$, fracture width, $w$, and fracture half- length, $x_{f}$. The RSM (response surface method) optimization method are used in evaluating the effect of operational these parameters on shale gas production. The RSM design variables and test run can be set up as in Table 2 and Table 3(Box and Draper. 1987; Anderson and Whitcomb. 2004).

Table 2 Factors and coded levels for RSM

\begin{tabular}{ccccc}
\hline \hline \multirow{4}{*}{ Factors } & $\begin{array}{c}S_{f}-X 1 \\
\text { /ft }\end{array}$ & $\begin{array}{c}w-X 2 \\
\text { /in }\end{array}$ & $\begin{array}{c}x_{f}-X 3 \\
/ \mathrm{ft}\end{array}$ \\
\hline \multirow{4}{*}{ Levels } & +Alpha level (1.682) & 250 & 0.2 & 400 \\
& High level (1) & 209.46 & 0.16 & 329.46 \\
& Zero level (0) & 150 & 0.11 & 225 \\
& Low level (-1) & 90.54 & 0.05 & 120.94 \\
& -Alpha level (-1.682) & 50 & 0.01 & 50 \\
\hline \hline
\end{tabular}

The response surface diagrams and sensitive analysis are presented in Figs. 3-5. The gas production rate increase with increase of fracture width and fracture half length, but increase with decrease of fracture spacing. Based on calculated sensitivities of design variables, the fracture spacing has the most dominant effect on productivity, followed by the fracture half length. The effect of fracture width (as well as fracture permeability in Eq. 5) on gas production is negligible.

Table 3 RSM test scheme

\begin{tabular}{|c|c|c|c|c|}
\hline \multirow[b]{2}{*}{$\begin{array}{l}\text { Test } \\
\text { No. }\end{array}$} & \multicolumn{3}{|c|}{ Fracture Geometry parameters ${ }^{*}$ (Actual-Coded factors) } & \multirow{2}{*}{$\begin{array}{c}\text { Predicted Production } \\
\mathrm{Mscf} / \mathrm{d}\end{array}$} \\
\hline & $\begin{array}{c}S_{f}-X 1 \\
/ \mathrm{ft}\end{array}$ & $\begin{array}{c}w-X 2 \\
\text { /in }\end{array}$ & $\begin{array}{c}x_{f}-X 3 \\
/ \mathrm{ft}\end{array}$ & \\
\hline 1 & $209.46(1)$ & $0.16(1)$ & $329.46(1)$ & 13.62 \\
\hline 2 & $209.46(1)$ & $0.16(1)$ & $120.94(-1)$ & 5.05 \\
\hline 3 & $209.46(1)$ & $0.05(-1)$ & $329.46(1)$ & 12.77 \\
\hline 4 & $209.46(1)$ & $0.05(-1)$ & $120.94(-1)$ & 4.93 \\
\hline 5 & $90.54(-1)$ & $0.16(1)$ & $329.46(1)$ & 72.39 \\
\hline 6 & $90.54(-1)$ & $0.16(1)$ & $120.94(-1)$ & 26.97 \\
\hline 7 & $90.54(-1)$ & $0.05(-1)$ & $329.46(1)$ & 65.66 \\
\hline 8 & $90.54(-1)$ & $0.05(-1)$ & $120.94(-1)$ & 25.99 \\
\hline 9 & $250(1.682)$ & $0.11(0)$ & $225(0)$ & 6.53 \\
\hline 10 & $50(-1.682)$ & $0.11(0)$ & $225(0)$ & 160.21 \\
\hline 11 & $150(0)$ & $0.2(1.682)$ & $225(0)$ & 18.27 \\
\hline 12 & $150(0)$ & $0.11(-1.682)$ & $225(0)$ & 18.06 \\
\hline 13 & $150(0)$ & $0.11(0)$ & $400(1.682)$ & 31.62 \\
\hline 14 & $150(0)$ & $0.11(0)$ & $50(-1.682)$ & 4.08 \\
\hline 15 & $150(0)$ & $0.11(0)$ & $225(0)$ & 18.01 \\
\hline
\end{tabular}

*Other parameters are the same with Table. 1.

$\mathrm{L}_{\mathrm{t}}$ and $\mathrm{L} 2$ depend on and vary with design parameters $\alpha, \beta$ and $\mathrm{R}$.

Fig. 6 presents the effect of fracture spacing of gas production. It shows a denser fracture distribution will drastically increase the gas production (nearly $800 \%$ in this case). Therefore, increasing the number of fracture as well as the density of fracture is an effective way to maximize the gas production rate. Fig. 7 shows the effect of fracture half-length on the gas production. A $400 \%$ production improvement can be achieved by increasing the fracture length, which implies creating a longer fracture by pumping a large volume of fluid is also a viable approach to improve the gas production. Fig. 8 shows the effect of fracture width (as well as fracture permeability) on gas production. Only $50 \%$ production improvement can be obtained by increasing the fracture width. Thus, there is no need to increase the investment on increasing the fracture width, like more powerful pump for fast pumping operation. Thus, the same results of single variable analysis are obtained against the RSM results. 


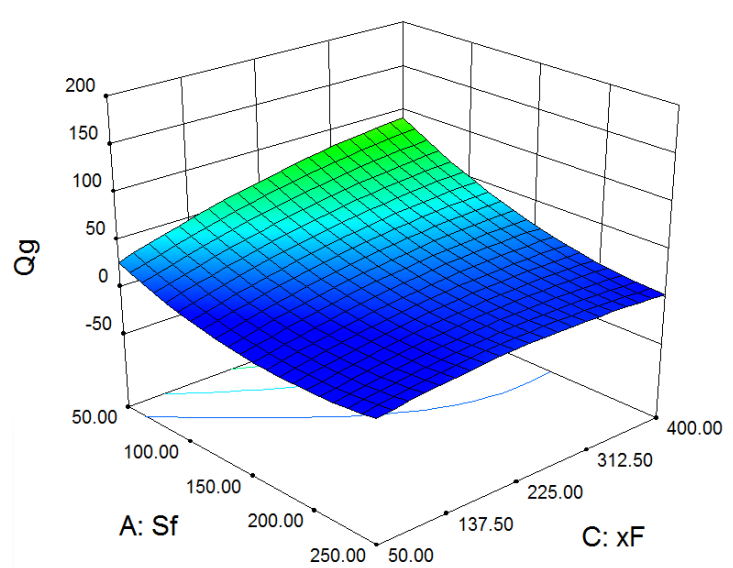

Fig. 3-Response surface for production rate as $\mathrm{S}_{\mathrm{f}}$ and $\mathrm{x}_{\mathrm{f}}$ vary as $\mathrm{S}_{\mathrm{f}}$ and $\mathrm{w}$ vary $(\mathrm{w}=0.11 \mathrm{inch})$

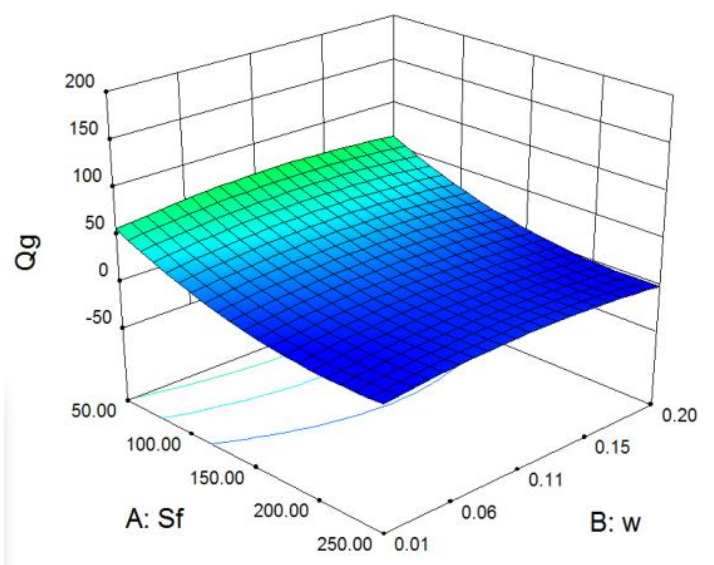

Fig. 4-Response surface for production rate $\left(\mathrm{x}_{\mathrm{f}}=225 \mathrm{ft}\right)$
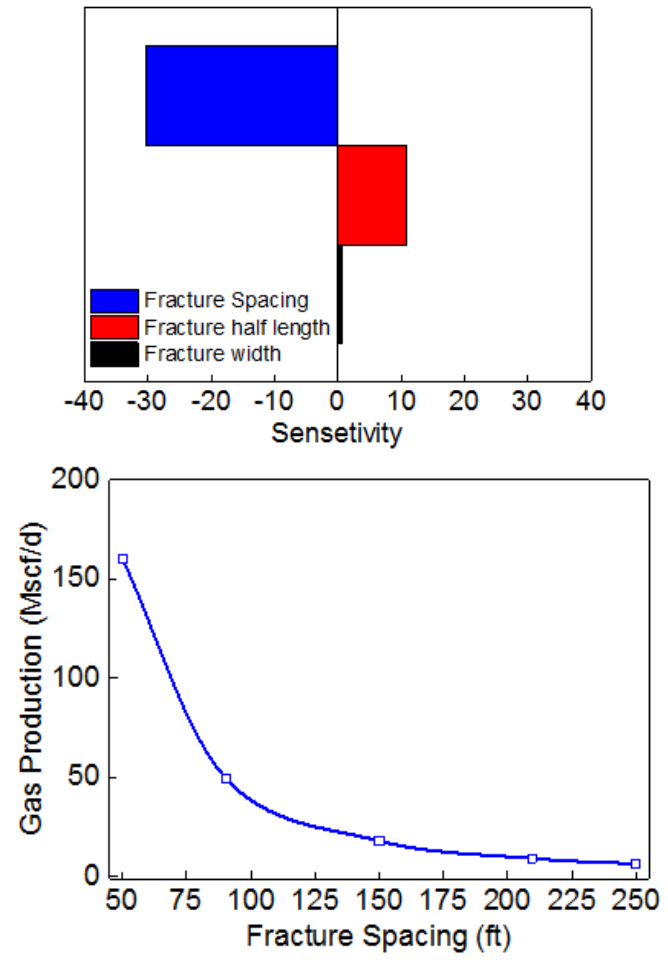

Fig. 5-Sensitivity analysis for fracture geometry parameters production rate

Fig. 6-Effect of fracture spacing on gas

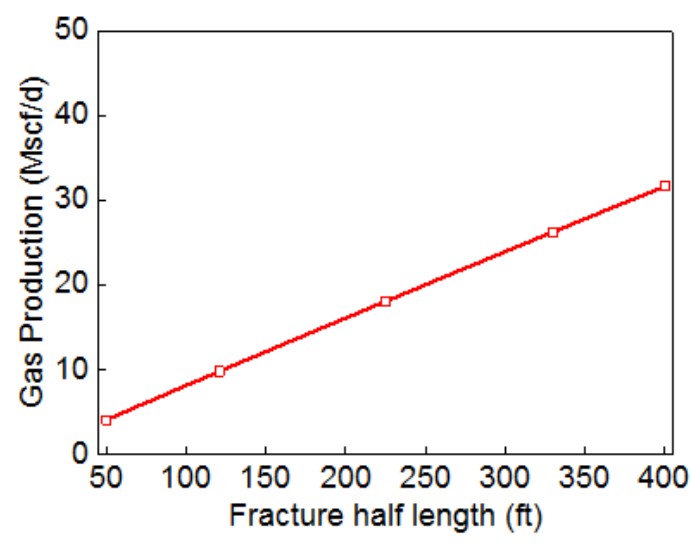




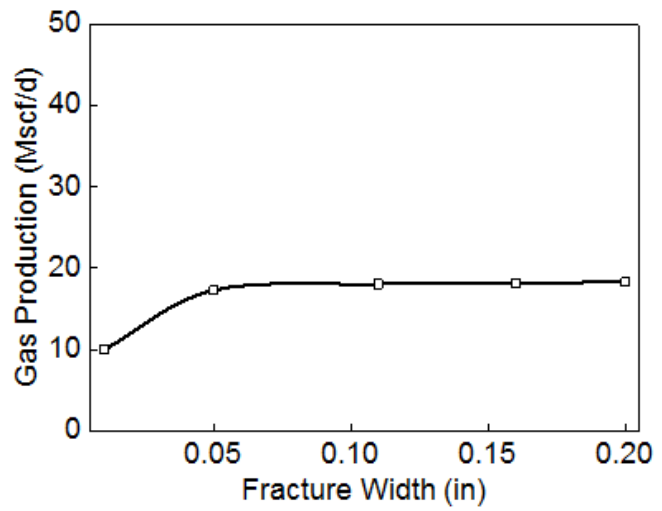

Fig. 7-Effect of fracture half-length on gas production rate Fig. 8-Effect of fracture width on gas production rate

\section{CONCLUSIONS}

Based on rigorous derivation, a simple and accurate model has been developed for estimating the longterm shale gas production. Several conclusions can be drawn accordingly:

- Case studies on a Fayetteville shale gas well indicates the difference between the production rates given by the model and field data are less than $10 \%$. The proposed is accurate enough for engineering application.

- Based on the sensitivity analysis of fracturing controlling factors, the fracture spacing has the most dominant effect on shale gas production rate, followed by the fracture half length.But the effect of fracture width on gas production is negligible. Thus, increasing the number of fracture and the volume of fracturing fluid are the effective ways in improving the production.

- This model provides reservoir engineers a simple and accurate tool for predicting, evaluating and optimizing the long-term performance of shale gas wells.

\section{ACKNOWLEDGMENTS}

The authors would like to express their appreciation to Dr. BoyunGuo (University of Louisiana at Lafayette) and Department of Petroleum Engineering (University of Louisiana at Lafayette) for their support of this work.

\section{Nomenclature}

$$
\begin{aligned}
c_{t} & =\text { total compressibility, } \mathrm{ft} \\
h & =\text { pay zone thickness, } \mathrm{ft} \\
k_{m} & =\text { matrix permeability, } \mathrm{md} \\
k_{f} & =\text { fracture permeability, } \mathrm{md} \\
n_{f} & =\text { number of fractures } \\
p_{w} & =\text { bottom hole pressure, } \mathrm{psi} \\
\bar{p} & =\text { reservoir average pressure, } \mathrm{psi} \\
S_{f} & =\text { fracture spacing, } \mathrm{ft} \\
T & =\text { formation temperature, } \mathrm{R} \\
x_{f} & =\text { fracture half length, } \mathrm{ft} \\
w & =\text { fracture width, inch }
\end{aligned}
$$

$$
\begin{aligned}
\phi & =\text { porosity, inch } \\
\square & =\text { fluid viscosity, } \mathrm{cp} \\
Q_{g} & =\text { shale gas production rate, Mscf/D }
\end{aligned}
$$

\section{REFERENCES}

[1] Anderson, M. J., Whitcomb, P. J., 2004. RSM Simplified: Optimizing Processes Using Response Surface Methods for Design of Experiments, CRC Press.

[2] Britt, L.K. and Smith, M.B., 2009, January. Horizontal well completion, stimulation optimization, and risk mitigation. In SPE Eastern Regional Meeting.Society of Petroleum Engineers.

[3] Box, G.E.P. and Draper, N. R., 1987.Empirical Model-Building and Response Surfaces. New York: Wiley.

[4] Fan, L., Thompson, J.W. and Robinson, J.R., 2010, January.Understanding gas production mechanism and effectiveness of well stimulation in the Haynesville Shale through reservoir simulation.In Canadian Unconventional Resources and International Petroleum Conference.Society of Petroleum Engineers.

[5] Cipolla, C.L., Lolon, E.P., Erdle, J.C. and Rubin, B., 2010. Reservoir modeling in shale-gas reservoirs.SPE reservoir evaluation \& engineering, 13(04), 638-653.

[6] Du, C., Zhang, X., Melton, B., Fullilove, D., Suliman, E.T.B., Gowelly, S.I., Grant, D. and Calvez, J., 2009, January.A workflow for integrated Barnett Shale gas reservoir modeling and simulation.In Latin American and Caribbean Petroleum Engineering Conference.Society of Petroleum Engineers.

[7] Li, J., Du, C. and Zhang, X., 2011, January. Critical evaluations of shale gas reservoir simulation approaches: single porosity and dual porosity modeling. In SPE middle east unconventional gas conference and exhibition. Society of Petroleum Engineers. 
[8] Dahaghi, A.K. and Mohaghegh, S.D., 2011, January. Numerical simulation and multiple realizations for sensitivity study of shale gas reservoirs. In SPE Production and Operations Symposium.Society of Petroleum Engineers.

[9] Freeman, C.M., Moridis, G.J., Ilk, D. and Blasingame, T.A., 2009, January.A numerical study of performance for tight gas and shale gas reservoir systems.In SPE Annual Technical Conference and Exhibition.Society of Petroleum Engineers.

[10] Guo, B. and Schechter, D.S., 1997, January.A simple and rigorous mathematical model for estimating inflow performance of wells intersecting long fractures.In SPE Asia Pacific Oil and Gas Conference and Exhibition.Society of Petroleum Engineers.

[11] Guo, B. et al, 2017. Petroleum production engineering, $2^{\text {nd }}$ edition.Gulf Professional Publishing.

[12] Song, B. and Ehlig-Economides, C.A., 2011, January. Rate-normalized pressure analysis for determination of shale gas well performance. In North American Unconventional Gas Conference and Exhibition.Society of Petroleum Engineers.
[13] Novlesky, A., Kumar, A. and Merkle, S., 2011, January. Shale Gas Modeling Workflow: From Microseismic to Simulation--A Horn River Case Study. In Canadian Unconventional Resources Conference.Society of Petroleum Engineers.

[14] Mattar, L., 2008, January. Production analysis and forecasting of shale gas reservoirs: case history-based approach. In SPE Shale Gas Production Conference.Society of Petroleum Engineers.

[15] Yu, W., Luo, Z., Javadpour, F., Varavei, A. and Sepehrnoori, K., 2014. Sensitivity analysis of hydraulic fracture geometry in shale gas reservoirs. Journal of Petroleum Science and Engineering, 113, 1-7.

[16] Yuan, H. and Zhou, D., 2010, January.A new model for predicting inflow performance of fractured horizontal wells.In SPE Western Regional Meeting.Society of Petroleum Engineers.

[17] Vargas, R.O., Lira-Galeana, C., Silva, D. and Manero, O., 2015.Inflow performance of wells intersecting long fractures with transient pressure and variable flow-rate behavior. Journal of Petroleum Science and Engineering, 136, 23-31.

\section{Appendix A-Matrix-to-Fracture Cross Flow in Fractured Reservoirs}

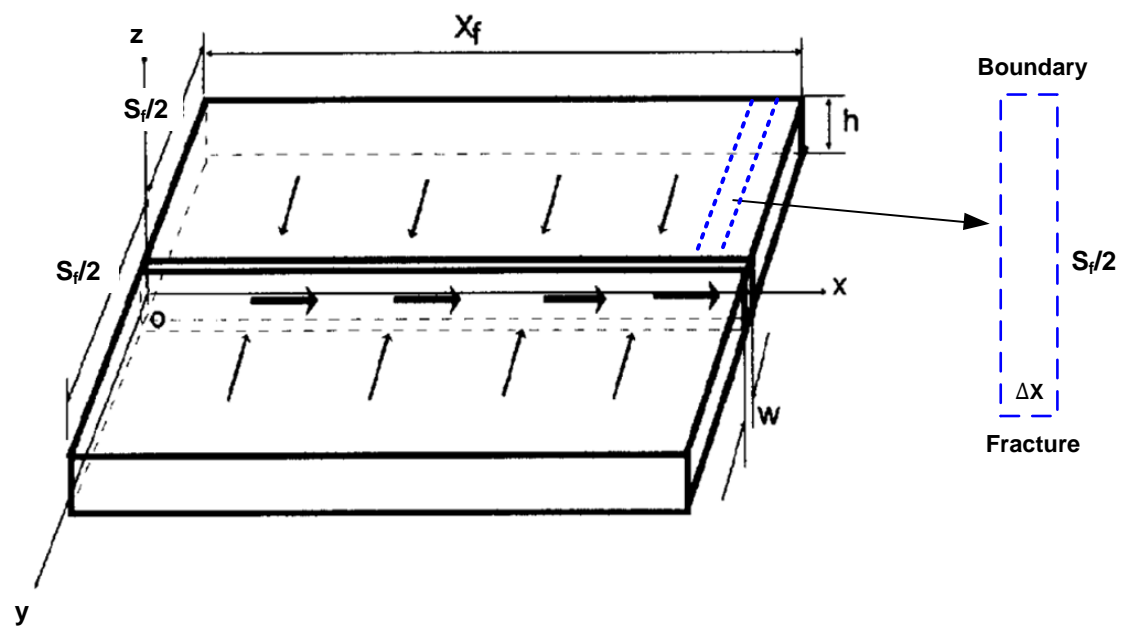

Fig. A-1 Geometry of a reservoir section drained by single wing of a fracture

\section{Matrix linear flow}

Based on the assumption of linear flow in matrix and uniform pressure distribution along fracture, the

$$
\begin{aligned}
& \frac{\partial}{\partial y}\left(\frac{\partial p}{\partial y}\right)=\frac{\mu \phi c_{t}}{k_{m}} \frac{\partial p}{\partial t} \\
& B C 1:\left.\quad \frac{\partial p}{\partial y}\right|_{y=S_{f} / 2}=0 \quad B C 2:\left.p\right|_{y=0}=p_{f}(x)
\end{aligned}
$$

governing equation for matrix flow can be expressed as follows:

For pseudo steady state flow, the pressure change is a constant. A simple mass balance relation can be 
expressed as follows using the assumptions of constant flow rate and compressibility (Dake, 1978):

$$
\frac{\partial p}{\partial t}=-\frac{q}{c_{t} V}=-\frac{q(x)}{c_{t}\left(S_{f} / 2\right) h \phi \Delta x}
$$

Substituting Eq. A-3 into Eq. A-1 gives:

$$
\frac{\partial}{\partial y}\left(\frac{\partial p}{\partial y}\right)=-\frac{q(x)}{c_{t}\left(S_{f} / 2\right) h \phi \Delta x} \frac{\mu \phi c_{t}}{k_{m}}=-\frac{2 q(x) \mu}{k_{m} S_{f} \Delta x h}
$$

Integrating Eq. A-4 gives:

$$
\frac{\partial p}{\partial y}=-\frac{2 q(x) \mu}{k_{m} S_{f} \Delta x h} y+C_{1}
$$

Applying boundary condition 1 (BC1) on Eq. 5 gives:

$$
\frac{\partial p}{\partial y}=\frac{q(x) \mu}{k_{m} \Delta x h}-\frac{2 q(x) \mu}{k_{m} S_{f} \Delta x h} y=\frac{q(x) \mu}{k_{m} \Delta x h}\left(1-\frac{2}{S_{f}} y\right)
$$

Integrating Eq. A-6 gives:

$$
p=\frac{q(x) \mu}{k_{m} \Delta x h}\left(y-\frac{y^{2}}{S_{f}}\right)+C_{2}
$$

Applying boundary condition 2 (BC2) on Eq. A-7 gives:

$$
p(x, y)=\frac{q(x) \mu}{k_{m} \Delta x h}\left(y-\frac{y^{2}}{S_{f}}\right)+p_{f}(x)
$$

The boundary pressure $p_{e}\left(x, S_{f} / 2\right)$ can be calculated as follows:

$$
p_{e}=\frac{q(x) \mu}{k_{m} \Delta x h}\left(\frac{S_{f}}{2}-\frac{\left(S_{f} / 2\right)^{2}}{S_{f}}\right)+p_{f}(x)=\frac{q(x) \mu S_{f}}{4 k_{m} \Delta x h}+p_{f}(x)
$$
9:

Thus, the flux (q)from matrix to fracture at a point $(\mathrm{x})$ in the fracture can be obtained by rearranging Eq. A-

$$
q(x)=\frac{4 k_{m} \Delta x h}{\mu S_{f}}\left[p_{e}-p_{f}(x)\right](\mathrm{A}-10)
$$

The velocity $(v)$ at a point $(\mathrm{x})$ in the fracture can be calculated as follows (Fig. A-1):

$$
v_{m}(x)=\frac{q(x)}{h \Delta x}=\frac{4 k_{m}}{\mu S_{f}}\left[p_{e}-p_{f}(x)\right]
$$

Therefore, the flow rate for two wings at a point $(\mathrm{x})$ in the fracture can be calculated as follows:

$$
Q_{m}(x)=2 \int_{x}^{x_{f}} \frac{4 k_{m}}{\mu S_{f}}\left[p_{e}-p_{f}(x)\right] \cdot h d x
$$
into A-8:

Also, the pressure at matrix in terms of boundary pressure $\left(p_{e}\right)$ can be expressed by substituting Eq. A-10

$$
p(x, y)=\frac{4}{S_{f}}\left[p_{e}-p_{f}(x)\right]\left(y-\frac{y^{2}}{S_{f}}\right)+p_{f}(x)
$$

\section{Fracture linear flow}

For linear fracture flow, the fluid velocity at the fracture should be the same with the velocity in the matrix:

$$
v_{f}(x)=\frac{Q_{m}(x)}{w h}=-\frac{k_{f}}{\mu} \frac{d p_{f}(x)}{d x}
$$

Substituting Eq. A-12 into A-14 gives:

$$
\frac{8 k_{m} h}{\mu S_{f}} \cdot \frac{1}{w h} \int_{x}^{x_{f}}\left[p_{e}-p_{f}(x)\right] d x=-\frac{k_{f}}{\mu} \frac{d p_{f}(x)}{d x}(\mathrm{~A}-15)
$$

Taking derivative with respect to $\mathrm{x}$ for Eq. A-15 gives: 


$$
\frac{8 k_{m}}{S_{f} w k_{f}}\left[p_{e}-p_{f}(x)\right]=\frac{d^{2} p_{f}(x)}{d x^{2}}
$$

The equation can be further simplified by:

$$
c=\frac{8 k_{m}}{S_{f} w k_{f}}, \quad p_{d}(x)=p_{e}-p_{f}(x)
$$

Thus, Eq. A-15 can be expressed as:

$$
\begin{aligned}
& \frac{d^{2} p_{d}(x)}{d x^{2}}=c p_{d}(x) \\
& B C 1:\left.\quad \frac{d p_{d}}{d x}\right|_{p_{d}=0}=0 \quad \text { (A-18) }
\end{aligned}
$$

Based on Guo and Schechter's derivation (1997), the solutionof Eq.A-18 can be expressed as follows:

$$
p_{f}(x)=p_{e}-\left(p_{e}-p_{w}\right) e^{\sqrt{c}\left(x-x_{f}\right)}
$$

\section{Multi-fractured horizontal gaswellinflow equation}

Substituting Eq. A-20 into Eq. A-13, the pressure distribution can be calculated as follows:

$$
p(x, y)=p_{e}-\left(p_{e}-p_{w}\right) e^{\sqrt{c}\left(x-x_{f}\right)}+\frac{4}{S_{f}}\left(p_{e}-p_{w}\right) e^{\sqrt{c}\left(x-x_{f}\right)}\left(y-\frac{y^{2}}{S_{f}}\right)
$$

Substituting Eq. A-20 into Eq. A-12 and integrating from 0 to $x_{f}$, the production rate for this fracture can be calculated as follows:

$$
Q=\frac{16 k_{m} h}{\mu S_{f} \sqrt{c}}\left(p_{e}-p_{w}\right)\left(1-e^{x_{f} \sqrt{c}}\right)
$$

The average pressure can be calculated as follows:

$$
\bar{p}=\frac{\int p d v}{\int d v}=\frac{\phi h \int_{0}^{x_{f}} \int_{0}^{S_{f} / 2} p(x, z) d z d x}{\phi h x_{f}\left(S_{f} / 2\right)}
$$

Substituting Eq. A-21 into Eq. A-22 gives:

$$
\bar{p}=p_{e}-\frac{p_{e}-p_{w}}{3 x_{f} \sqrt{c}}\left(1-e^{-x_{f} \sqrt{c}}\right)
$$

Solving $\mathrm{P}_{\mathrm{e}}-\mathrm{P}_{\mathrm{w}}$ from Eq. A-22 and substituting the results into Eq. A-24 gives the inflow performance in terms of average pressure:

$$
Q=\frac{16 k_{m} h\left(\bar{p}-p_{w}\right)}{\mu S_{f} \sqrt{c}\left[\frac{1}{1-e^{-\sqrt{c} x_{f}}}-\frac{1}{3 x_{f} \sqrt{c}}\right]}
$$

For multi-fractured $\left(n_{f}\right)$ horizontal well, the general inflow performance can be expressed as follows:

$$
Q=\frac{16 n_{f} k_{m} h\left(\bar{p}-p_{w}\right)}{\mu S_{f} \sqrt{c}\left[\frac{1}{1-e^{-\sqrt{c} x_{f}}}-\frac{1}{3 x_{f} \sqrt{c}}\right]}, \quad c=\frac{8 k_{m}}{S_{f} w k_{f}}
$$

For gas well, the gas production rate in standard conditions and field units can be expressed as follows:

$$
Q_{g}=\frac{T_{0}}{p_{0}} \frac{p}{T} Q=\frac{T_{0}}{p_{0}} \frac{\bar{p}+p_{w f}}{2} \frac{Q}{T} \text { (A-27) }
$$

Substituting Eq. A-27 into Eq. A-26 gives: 


$$
\begin{aligned}
& Q_{g}=\frac{T_{0}}{p_{0}} \frac{p}{T} Q=\frac{T_{0}}{2 p_{0}} \frac{\bar{p}+p_{w f}}{T} \frac{16 n_{f} k_{m} h\left(\bar{p}-p_{w}\right)}{\mu S_{f} \sqrt{c}\left[\frac{1}{1-e^{-\sqrt{c x_{f}}}}-\frac{1}{3 x_{f} \sqrt{c}}\right]} \\
& =\frac{5.87 \times 10^{-5} n_{f} k_{m} h\left(\bar{p}^{2}-p_{w}^{2}\right)}{\mu T S_{f} \sqrt{c}\left[\frac{1}{1-e^{-\sqrt{c} x_{f}}}-\frac{1}{3 x_{f} \sqrt{c}}\right]}
\end{aligned}
$$

Zheng Zhang. "A Simple Analytical Model for Estimating Long-term Productivity of Multifractured Shale Gas Wells." International Journal of Engineering Research and Applications (IJERA) 7.7 (2017): 06-15. 